\title{
Mechanical characterization of heat treated Al2219 hybrid composites
}

\section{Gowrishankar M C ${ }^{1}$, Sathyashankara Sharma ${ }^{1 *}$, B K Pavan ${ }^{1}$, Kamath Kiran ${ }^{1}$ and Kumar Rajendra ${ }^{1}$, Pavan Hiremath ${ }^{1}$, Manjunath Shettar ${ }^{1}$}

\author{
${ }^{1}$ Department of Mechanical and Manufacturing Engineering, \\ Manipal Institute of Technology, Manipal Academy of Higher Education, \\ Manipal, Karnataka, India, 576104 \\ Phone: 9740540928; Fax: 91-820-2571071 \\ *Email: ss.sharma@manipal.edu
}

\begin{abstract}
Aluminium alloy matrix composites with $\mathrm{Al}_{2} \mathrm{O}_{3}$ reinforcements exhibit superior mechanical properties and utilize in several demanding fields' viz., automobile, aerospace, defense, sports equipment, electronics and bio-medical. The present work emphasizes on improvement of microstructure and mechanical properties of age hardened graphite and alumina reinforced $\mathrm{Al}$ alloy matrix hybrid composites. Different composites with a constant carbon content of 1 weight $\%$ and $0,2,4$ and 6 weight $\% \mathrm{Al}_{2} \mathrm{O}_{3}$ as reinforcements are fabricated by using stir casting technic and tested for hardness, tensile and impact strength. Scanning electron microscopy (SEM) is performed to analyse the failure mode under tensile load. All the composites are subjected to age hardening treatment with solutionising temperature of $530^{\circ} \mathrm{C}$ and aging temperatures of 100 and $200^{\circ} \mathrm{C}$. The peak hardness of the composites at two aging temperatures are noted. Tensile and impact tests are conducted for the peak aged specimens. Results show substantial increase in the hardness of the age hardened specimens in the range of $34-44 \%$ in comparison with the as cast specimens. Result analysis shows increase in tensile strength (upto 40\%) and decrease in impact resistance (upto $33 \%$ ) with the increase in weight $\%$ of reinforcements. As the aging temperature increases a reduction in tensile strength and impact resistance is observed in each composites.
\end{abstract}

Keywords: Al 2219; Alumina; Stir casting; Age hardening; Tensile strength; Impact strength; SEM

\section{INTRODUCTION}

Aluminium alloys have been taking the place of steels in the areas where there is requirement for lower weight and very less maintenance. Structural materials need to have lower costs, higher strength to weight ratio, along with higher fatigue resistance [1]. Strength of aluminium alloys is increased by precipitation strengthening which is an important hardening method precipitation strengthening, the second phase spontaneously precipitated within the matrix phase [2]. Ternary aluminium-copper- magnesium systems are the main reactions in precipitation hardening. Commercially important Al alloys have copper as main alloy element and phase reactions are those between the aluminium solid solutions and intermetallic phases [3]. 
Aluminium matrix composites are gaining popularity due to cost effectiveness and added advantages like isotropic properties and the possibility of secondary processing facilitating fabrication of secondary components [4]. When compared to the unreinforced alloys, cast aluminum matrix particle reinforced composites have higher specific strength, specific modulus and good wear resistance. Liquid metallurgy route by casting can be used to prepare the particulate composite by injecting the reinforcing particles into liquid matrix. Stir casting process is commonly used as it is very cheap and simple as compared to rest of the liquid state production routes. But in this process there is high chance of non-uniform distribution of the particulate due to poor wettability and gravity regulated segregation [5].

The main objective of this work is to fabricate and characterize $\mathrm{Al}_{2} \mathrm{O}_{3}$ and graphite reinforced Al alloy matrix hybrid composites,

\section{MATERIALS AND METHODS}

\section{Matrix and reinforcement materials}

Table 1 shows the nominal composition of matrix materials ( $\mathrm{Al} 2219$ ). Matrix material was procured from Fenfe Metallurgicals, located at Uttarhalli, Bengaluru. Alumina and Graphite were used as the reinforcing materials.

Table 1. Composition (Wt. \%) of Al2219 alloy.

\begin{tabular}{lccccccc}
\hline \multicolumn{1}{c}{ Material } & $\mathrm{Cr}$ & $\mathrm{Cu}$ & $\mathrm{Fe}$ & $\mathrm{Mg}$ & $\mathrm{Mn}$ & $\mathrm{Si}$ & $\mathrm{Al}$ \\
\hline Wt. \% (Standard) & $0.1 \mathrm{max}$ & $3.8-4.9$ & $0.5 \max$ & 1.2 & $0.3-0.9$ & 0.5 max & Balance \\
Wt. \% (Actual) & 0.06 & 4.1 & 0.1 & 1.3 & 0.4 & 0.5 & Balance \\
\hline
\end{tabular}

\section{Stir casting technique}

Four different composite castings of $1 \mathrm{~kg}$ each in different proportions are intended to cast by liquid stir casting process route. Aluminium 2219 was melted in a resistance heated muffle furnace and casted in a clay graphite crucible. For this the melt temperature was raised to $1023 \mathrm{~K}$. After 2-3 hours the Aluminium ingots melt completely and are in liquid state. The molten metal is degassed by purging $\mathrm{C}_{2} \mathrm{Cl}_{6}$ (hexachloro ethane) powder in the clay graphite crucible. Degasification is the removal of dissolved gases from liquids, especially water or aqueous solutions, in the fields of science and engineering. Meanwhile the graphite and alumina powders are kept for preheating at around $200^{\circ} \mathrm{C}$ for 1 hour. The moulds are cleaned using Acetone and a thin layer of liquid mixture of graphite powder is coated on the inner surface of the moulds. Then the moulds are placed in oven for preheating at $100^{\circ} \mathrm{C}$ for 1 hour. Preheated alumina and graphite powders are mixed in the red hot liquid Al 2219 kept in the crucible in the required composition. The stirrer is fixed in the muffle furnace and is constantly rotated at $100 \mathrm{rpm}$. A vortex is formed due to constant stirring of molten metal. Preheated Alumina and graphite powder mixture is poured into the crucible at the vortex of the molten metal. The stirring is continued for 10 minutes such that all the constituent material get mixed properly with the base metal that is Al 2219. Later the red hot liquid 
mixture is poured in to dies and allowed it for solidification. Then the casting dies are separated after allowing it to cool for 5 hours and the castings are removed.

\section{Composition (Wt. \%) of composites cast}

The four castings are prepared by varying Wt. \% as shown in Table 2.

Table 2. Details of reinforcement for the preparation of composites

\begin{tabular}{|c|c|c|}
\hline Matrix & Wt.\% C & Wt.\% $\quad \mathrm{Al}_{2} \mathrm{O}_{3}$ \\
\hline Al 2219 & 1 & 0 \\
\hline Al 2219 & 1 & 2 \\
\hline Al 2219 & 1 & 4 \\
\hline Al 2219 & 1 & 6 \\
\hline
\end{tabular}

\section{Age hardening/precipitation hardening treatment}

Tensile, hardness and Charpy impact test specimens are prepared as per ASTM E8M, ASTM 18-02 and ASTM E23-020 standard respectively [3]. The specimens are placed in electric furnace at $530^{\circ} \mathrm{C}$ for 2 hours for solutionising process. It is then rapidly quenched in water and the specimens are placed in hot air oven maintained at $100^{\circ} \mathrm{C}$. After every half an hour a specimen from different composition is removed from oven and is rapidly quenched in water. The specimens are immediately tested for its hardness using Rockwell hardness test of scale B (HRB). Thus specimens are kept in hot air oven for 9 hours and the hardness readings are recorded at a time interval of every half an hour till the peak hardness value is observed. A graph of time vs. hardness values are plotted and peak hardness values are noted down for each of the composition. The procedure is repeated with hot air oven temperature set at $200^{\circ} \mathrm{C}$.

\section{RESULTS AND DISCUSSIONS}

\section{Rockwell hardness test}

Rockwell hardness tester contains a diamond cone indenter having an included angle of $120^{\circ}$ and a radius of curvature at the tip of $0.2 \mathrm{~mm}$, or a hardened steel or hardened ball having a diameter of $1.5875 \mathrm{~mm}$ is forced into the surface of a test piece in two steps, and the permanent depth of indentation under preliminary test force after removal of additional test force is measured [6]. Equipment uses a steel ball indenter with $100 \mathrm{~kg}$ and $10 \mathrm{~kg}$ as major and minor load respectively. 
Table 3. HRB values of various compositions and different conditions.

\begin{tabular}{cccc}
\hline $\begin{array}{c}\text { Composites with } \\
\text { varying Wt.\% of } \\
\mathrm{Al}_{2} \mathrm{O}_{3}\end{array}$ & As Cast & $\begin{array}{c}100^{\circ} \mathrm{C} \text { aged } \\
\text { composites }\end{array}$ & $200^{\circ} \mathrm{C}$ aged composites \\
\hline 0 & 50 & 54 & 72 \\
2 & 52 & 74 & 73 \\
4 & 55 & 76 & 74 \\
6 & 57 & 79 & 78 \\
\hline
\end{tabular}

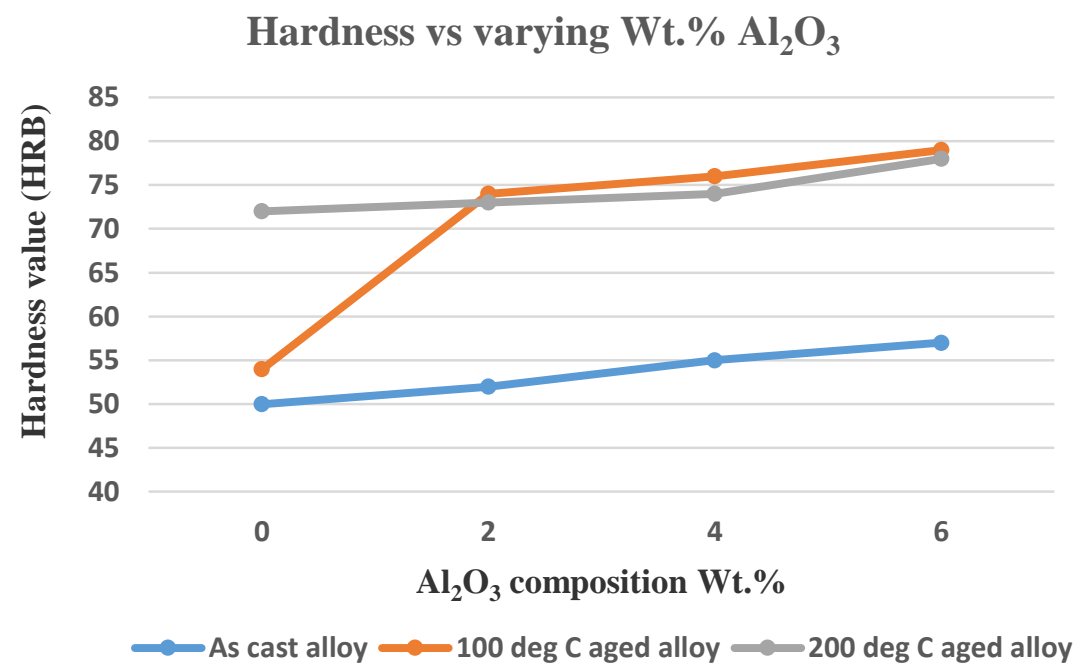

Figure 1. Hardness vs varying $\mathrm{Wt} . \% \mathrm{Al}_{2} \mathrm{O}_{3}$.

From the figure 1 of as cast condition, it can be seen that there is increase in hardness values with the addition of reinforcements when compared to the unreinforced alloy. With the increase in weight percentage of $\mathrm{Al}_{2} \mathrm{O}_{3}$, the hardness value increases. Increased content of reinforcement in the matrix alloy leads to higher dislocation densities during solidification due to the vast difference in the thermal expansion coefficients of reinforcement and the matrix alloy which forms a large residual strain due to the mismatch which in turn contributes to the microstructural changes and hence improves mechanical properties of the composites [7].

Considering table 3 , it is observed that at lower aging temperature $\left(100^{\circ} \mathrm{C}\right)$ the diffusion rate is slow but there may be more number of transition embryo type unstable phases in the process of solid solution strengthening, hence to obtain peak hardness value, the process takes more time with high value of peak hardness. At $200^{\circ} \mathrm{C}$ hardening occurs quickly due to rapid diffusion with lesser number of transition phases. So peak hardness value is also less. 
Al 2219 matrix composite is very suitable to age hardening irrespective of lower or higher aging temperature. Clearly the composites show accelerated rate of aging kinetics as compared to unreinforced matrix alloy. Aging kinetics gets accelerated in the composites with increase in wt. \% of reinforcements. Aging is accelerated due to the presence of areas with a high concentration of dislocation close to $\mathrm{Al} 2219$ matrix \& $\mathrm{Al}_{2} \mathrm{O}_{3}$ reinforcements interface. These high density locations provide assorted phase nucleation sites for the intermediate phases \& prominent diffusion paths for the solute atoms [3]. When compared to base alloy, composites show drastic increase in the hardness in as cast $\&$ treated conditions. At the same time increase in weight percentage of $\mathrm{Al}_{2} \mathrm{O}_{3}$ in the composites gives positive effect on hardness value. It can be seen from the above results that there is a great influence of artificial aging on the hardness of matrix alloy as well as composites. [2].

\section{Microstructure Studies}

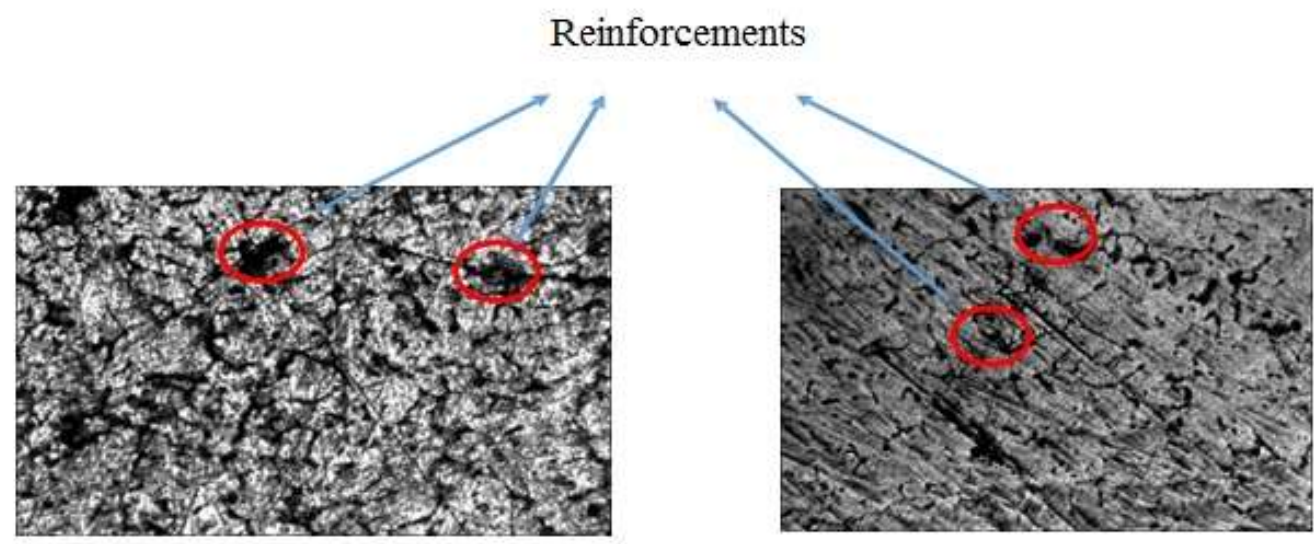

(a)

\section{Reinforcements}

(b)

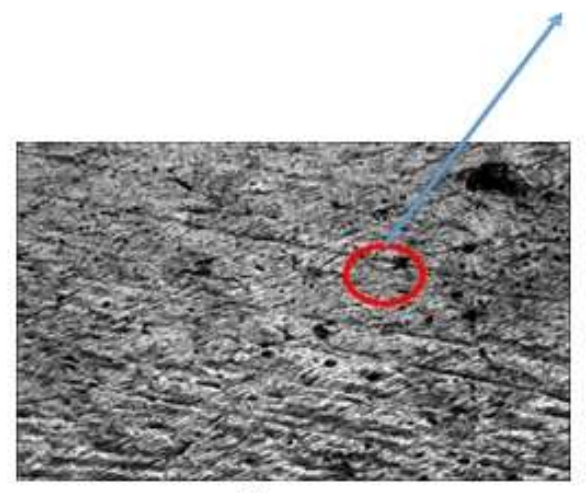

(c)

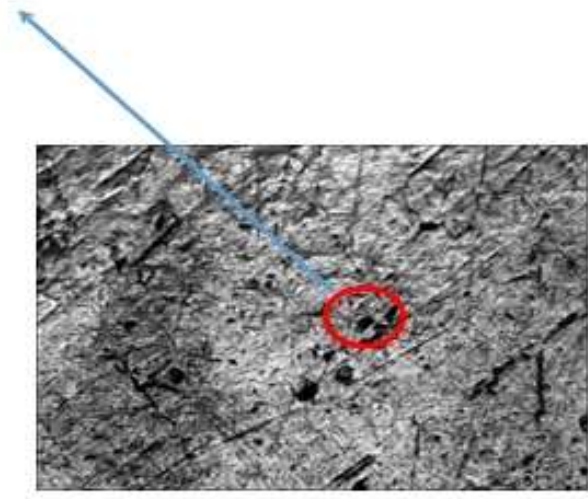

(d)

Figure 2. Composites containing (a) $0 \mathrm{Wt} \% \mathrm{Al}_{2} \mathrm{O}_{3}$, (b) $2 \mathrm{Wt} \% \mathrm{Al}_{2} \mathrm{O}_{3}$, (c) $4 \mathrm{Wt} \%$ $\mathrm{Al}_{2} \mathrm{O}_{3}$ and (d) $6 \mathrm{Wt} \% \mathrm{Al}_{2} \mathrm{O}_{3}$.

Figures 2 shows the microphotographs of cast $\mathrm{Al} 2219-\mathrm{C}-\mathrm{Al}_{2} \mathrm{O}_{3}$ with $0,2,4,6 \mathrm{Wt} \%$ of $\mathrm{Al}_{2} \mathrm{O}_{3}$ composites respectively. From figure, it can be seen that, there is fairly uniform distributions of reinforcements in the respective matrix. Further these figures reveal the 
homogeneity and better dispersion of the cast composites. The microphotograph also clearly reveals the increased filler contents in the composites.

\section{SEM Analysis}

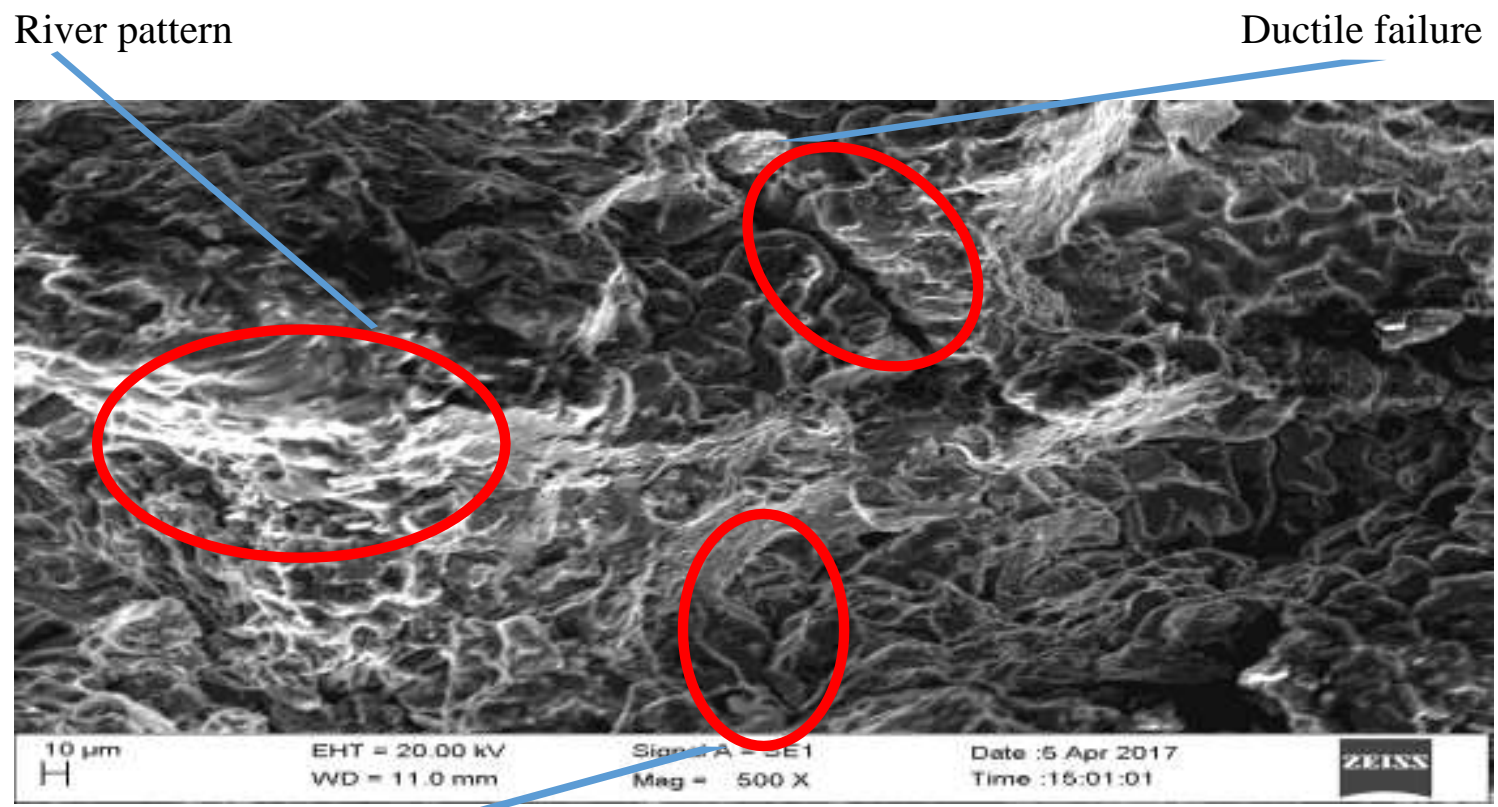

Dimples brittle crack

Figure 3. SEM image of fracture surface of $4 \% \mathrm{Al}_{2} \mathrm{O}_{3}$ tensile specimen.

The fracture surface of SEM image (figure 3) shows finer dimples, coarser dimples, cracks, river pattern. Appearance of finer dimples in micrograph is the indication of higher strength and toughness [6]. Coarse dimples is the indication of higher ductility which will lead to ductile fracture. River pattern is the indication of ductile and brittle (mixed) mode of failure. Overall conclusion about the failure mode is totally mixed one (ductile and brittle). 

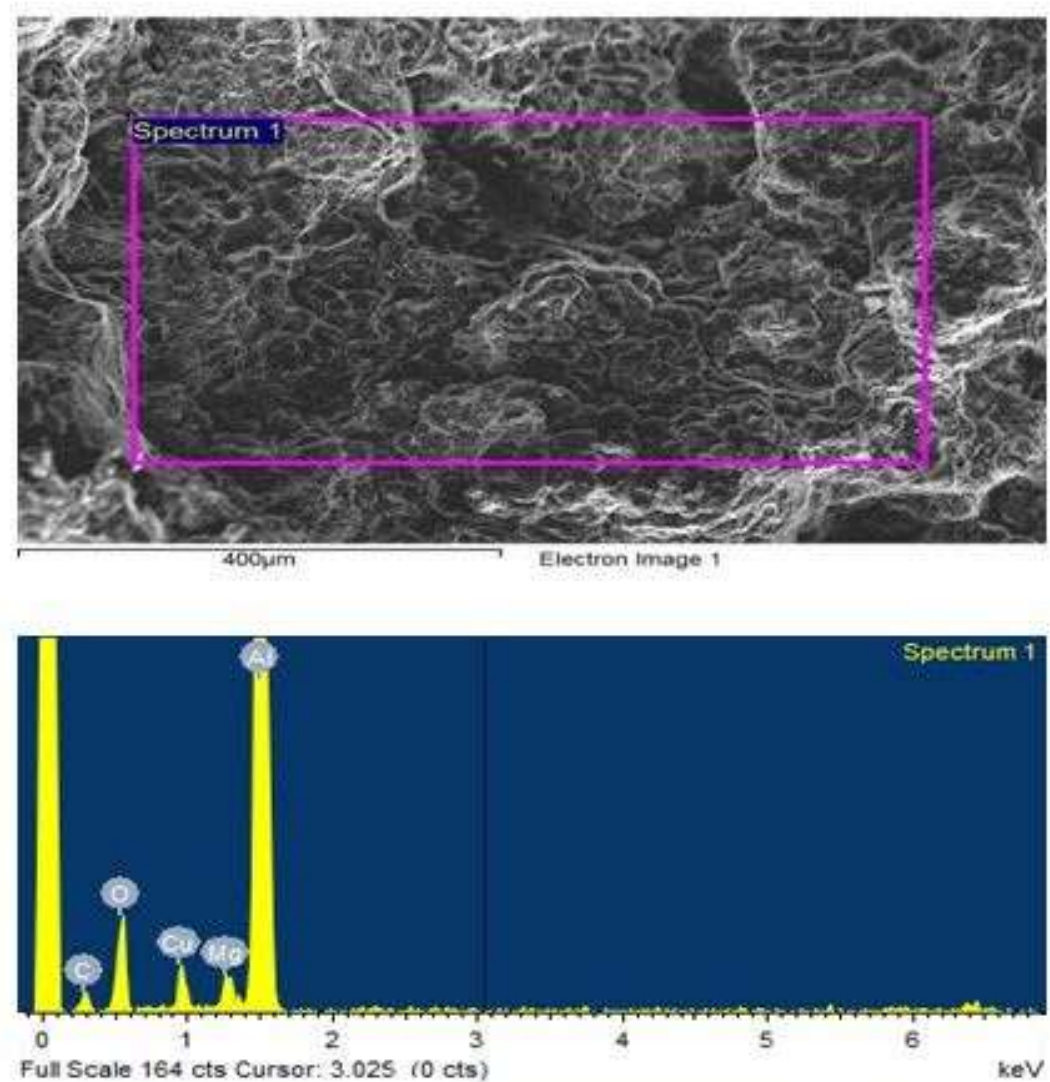

Figure 4. EDX analysis of fracture surface of $4 \mathrm{Wt} . \% \mathrm{Al}_{2} \mathrm{O}_{3}$.

Figure 4 shows the XRD analysis of fracture surface where the presence of $\mathrm{Cu}$ and $\mathrm{Mg}$ are observed in the solid solution of matrix material with $\mathrm{Al}$ as solvent material (larger intensity peak). Oxygen presence also observed due to $\mathrm{Al}_{2} \mathrm{O}_{3}$ reinforcement.

\section{Charpy impact test}

Table 4 and figure 5 show the impact resistance (Energy in Joules) of composites in as cast and age hardened conditions. In as cast and high temperature aged conditions there is no much changes in the impact resistance of the composite with increase in reinforcement amount. Lower temperature aged one shows better impact values, it may be due to the evenly distributed lesser number of fine intermetallics in the matrix [3]. 


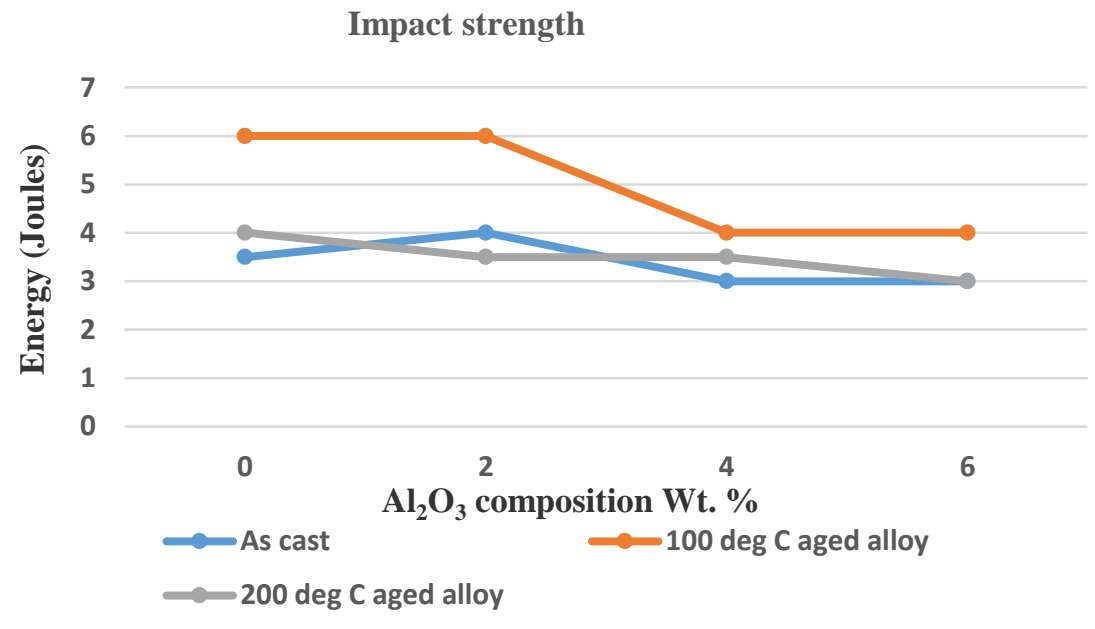

Figure 5. Line chart of impact values.

Table 4. Charpy impact test readings (Energy in Joules).

\begin{tabular}{clcc}
\hline $\begin{array}{c}\text { Composites with } \\
\text { varying Wt. } \% \text { of }\end{array}$ & \multicolumn{3}{c}{ Energy $(\mathrm{J})$} \\
\cline { 2 - 4 } $\mathrm{Al}_{2} \mathrm{O}_{3}$ & As cast & $100^{\circ} \mathrm{C}$ & $200^{\circ} \mathrm{C}$ \\
\hline 2 & 4 & 6 & 3.5 \\
4 & 3 & 4 & 3.5 \\
6 & 3 & 4 & 3 \\
\hline
\end{tabular}

Table 5. Engineering ultimate tensile strength (UTS) values for different composition in $\mathrm{MPa}$.

\begin{tabular}{cccc}
\hline & & UTS (MPa) & \\
varying Wt.\% of $\mathrm{Al}_{2} \mathrm{O}_{3}$ & As cast & $100^{\circ} \mathrm{C}$ & $200^{\circ} \mathrm{C}$ \\
\cline { 2 - 4 } & 160 & 225 & 180 \\
2 & 191 & 231 & 270 \\
4 & 135 & 220 & 205 \\
6 & 186 & 320 & 307 \\
\hline
\end{tabular}

Lower temperature peak aged specimens of lesser reinforcement additions show highest consistent impact resistance, it may be due to the presence of finely distributed strengthening intermetallic phases during secondary precipitation $[7,8]$. At higher temperature of aging the 
impact resistance of the composite further decreases due to the precipitation of slightly coarser intermetallic in the matrix. The same argument holds good in the case of composites where the reinforcement content increases more than $2 \mathrm{Wt} . \%$. The brittle nature of the reinforcement and precipitates (intermetallic) contributes more on the strength factor with considerable reduction in impact resistance which is seen in the figure 9 and 10.

\section{Tensile Test}

As shown table 5 and figure 6, ultimate tensile strength is maximum for $100^{\circ} \mathrm{C}$ aging temperature and decreases at $200^{\circ} \mathrm{C}$ aging temperatures. With the increase in Wt. $\%$ of $\mathrm{Al}_{2} \mathrm{O}_{3}$ the ultimate tensile strength increases [1]. The ultimate tensile strengths of artificial aged alloys are more as compared to the ones which are as cast. The attributing factor for this behavioral change may considered as the sluggish diffusion rates at these temperatures, where the solute atoms have limited mobility. The atoms migration may be only a few tens of interatomic distances $[9,10]$.

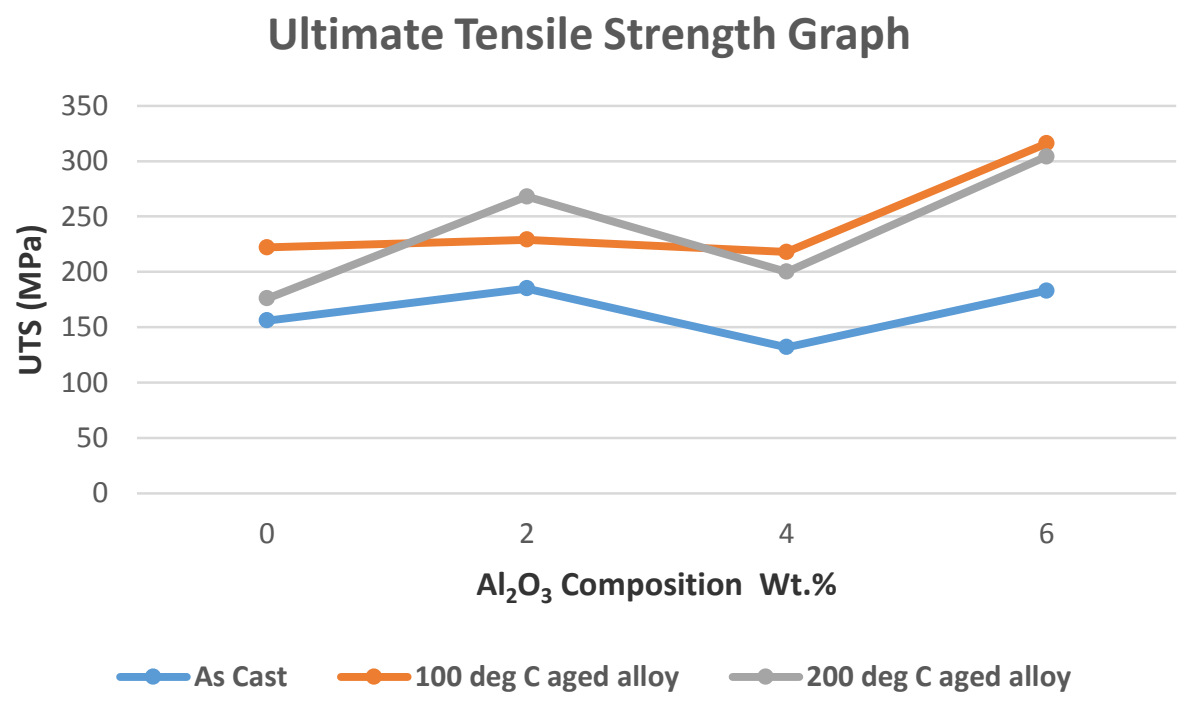

Figure 6. Comparative line chart of UTS.

This gives rise to formation of fine scale transition structures. The fine precipitates so formed within the matrix lead to local internal micro level distortions and strain fields which restrict dislocation motion, this in turn increases the strength of the alloy $[11,12]$.

\section{CONCLUSIONS}

The present research presents the effect of aging on properties of solutionised composites. The age hardening of composites, the study identifies its characterization in two different aging temperatures with time. The result confirms the standard behavior of age hardenable metal matrix composites. Following conclusions are reached as the research output. Lower the aging temperature, higher is the peak hardness value and longer is the time required for peak aging and to obtain peak hardness maximum time of 7.5 hours for $100^{\circ} \mathrm{C}$ and 5.5 hours 
for $200^{\circ} \mathrm{C}$ was required for $0 \mathrm{Wt} . \% \mathrm{Al}_{2} \mathrm{O}_{3}$ composite. As the weight percentage of reinforcement increases, increase in the nucleation sites for precipitation of intermetallic helps to increase the peak hardness value. When compared to as cast composite, maximum of $44 \%$ increase in peak hardness was found for 0 wt. $\% \mathrm{Al}_{2} \mathrm{O}_{3}$ composite aged at $100^{\circ} \mathrm{C}$. Micro structure reveals well dispersion of reinforcements in the alloy matrix. SEM analysis reveals the tensile failure mode as mixed one. As the weight percentage of reinforcement increases, impact resistance tends to decrease and maximum of $12.5 \%$ decrease in impact strength was found for $2 \mathrm{Wt} . \% \mathrm{Al}_{2} \mathrm{O}_{3}$ aged at $200^{\circ} \mathrm{C}$. As the weight percentage of reinforcement increases, tensile strength tends to first decrease and then increase and a maximum of $72 \%$ for $6 \mathrm{Wt} . \% \mathrm{Al}_{2} \mathrm{O}_{3}$ composite aged at $100^{\circ} \mathrm{C}$ was found when compared to as cast composite.

\section{REFERENCE}

[1] Baradeshwaran A, Elaya Perumal A. Study on mechanical and wear properties of Al7075/ $\mathrm{Al}_{2} \mathrm{O}_{3}$ /graphite hybrid composites. Journal of Materials Processing Technology 2013; 56: 464-471.

[2] Egallad E M, Zhang Z, Chen X G. Effect of two step aging on the mechanical properties of AA2219 DC cast alloy. Journal of Alloys and Compounds 2014; 625:213-220.

[3] Kaçar H, Atik E, Meriç C. The effect of precipitation hardening condition on wear behaviors of 2024 aluminum wrought alloy. Journal of Materials Processing Technology 2003; 142 (3) : 762- 766.

[4] Huda Z, Zaharinie T. Kinetics of grain growth in 2024-T3: An aerospace aluminum. Journal of Alloys and Compounds 2009; 478: 128-132.

[5] Ramesh C S, Safiulla M. Wear behavior of hot extruded Al6061 based composites. Journal of Alloys and Compounds 2009; 263: 629-635.

[6] Kulkarni, Krishnamurthy K, Deshmukh S P, Mishra R S. Fracture behavior of two stage stir cast Al6061composites. Journal of material research 2004; 2:27-32.

[7] Hussain F, Abdullah S, Nuawi MZ. Effect of temperature on fatigue life behaviour of aluminium alloy AA6061 using analytical approach. Journal of Mechanical Engineering and Sciences $2016 ; 10(3)$ :2324-2235.

[8] Rajan T V, Sharma C P, Ashok Sharma, Heat treatment principles and techniques. Delhi: PHI learning private limited 2014:97-107.

[9] Krishna K, Chawla. Composite materials -Science and Engineering, New York: Springer 2014:35-87.

[10] Alok Nayar, Testing of metals, New Delhi: Tata McGraw Hill publishing company Limited, 2005:87-90.

[11] Avner S H. Introduction to Physical metallurgy, Michigan: McGraw-Hill. 1974:204210.

[12] Sathyashankara S, Achutha K, Gowri M C, Rakesh T C, Raja H, Krishna C, Manjunath S. Tensile fractography of artificially aged Al6061-B ${ }_{4} \mathrm{C}$ composites. Journal of Mechancial Engineering and Sciences 2018; 12: 3866-3875. 